\title{
AWAS BAHAYA SERANGAN LALAT BUAH PADA TANAMAN JERUK
}

\author{
I.N. Wijaya ${ }^{1}$ dan W. Adiartayasa ${ }^{2}$
}

\begin{abstract}
ABSTRAK
Sebagian besar penduduk Desa Katung, Kecamatan Kintamani, Kabupaten Bangli sebagai petani jeruk yang tergabung dalam kelompok Subak Abian Kerta Winangun yang beranggotakan 97 orang. Pertanaman jeruk di daerah ini sangat berhasil, sehingga pendapatannya meningkat. Namun belakangan, petani resah karena tanaman jeruknya terserang hama lalat buah. Oleh karena itu perlu diadakan penyuluhan dan pelatihan tentang pengelolaan hama lalat buah pada tanaman jeruk. Adapun tujuan penyuluhan dan pelatihan ini untuk memberikan pengetahuan dan keterampilan kepada para petani setempat tentang bahaya serangan hama lalat buah serta pengendaliannya pada tanaman jeruk meliputi : gejala serangan, faktor-faktor yang mempengaruhi perkembangan lalat buah dan cara pengendaliannya. Metode yang digunakan dalam pelatihan ini adalah penyampaian materi di ruangan dan praktek di perkebunan jeruk. Kegiatan penyuluhan dan demontrasi dilaksanakan hari Sabtu, tanggal 12 Agustus 2017 mulai pukul 10.00 sampai 14.00 WITA, bertempat di Balai Banjar Katung, Kecamatan Kintamani, Kabupaten Bangli. Pelatihan ini dipandu oleh 4 (empat) orang pelatih yang berasal dari Program Studi Agroekoteknologi Fakultas Pertanian Universitas Udayana. Pelatihan diikuti diikuti oleh 69 orang peserta. Penceramah memaparkan materinya dengan menggunakan alat peraga berupa power point dan menggunakan spesimen berupa gejala serangan lalat buah. Kemudian dilanjutkan dengan praktek lapangan selama 60 menit. Dalam pelaksanaan pelatihan tersebut, petani sangat antusias untuk mengikuti penyuluhan. Hal ini terbukti dari banyaknya pertanyaan-pertanyaan yang diajukan. Untuk mengetahui keberhasilan kegiatan ini, maka dilaksanakan evaluasi dengan pengisian kuisioner sebelum dan sesudah pelatihan.
\end{abstract}

Kata kunci: Pelatihan, lalat buah, desa Katung ABSTRACT
The majority of Katung villagers, Kintamani district, Bangli regency as farmers citrus in groups subak abian
Kerta Winangun. Citrus crops in this area highly successful, so their income rose. But later, farmers worried
because the citrus attack by fruit flies. Hence badly needed counseling and training on the management fruit
flies pest e in citrus crops. As for the purpose of information and this training to give knowledge and skills to
the local farmers about the dangers of fruit flies attacks and illness and their their control: symptoms include
attacks affecting factor the development fruit flies, the way, how pengendaliannya .Methods used in this
training was material delivery in the room and practice plantation in citrus. As for the purpose of information
and this training to give knowledge and skill for the local farmers about the dangers of pest attacks their contol
in citrus plants includes: symptoms attack, factors affecting the development pest, and the way to control. This
training guided by 4 ( four ) persons coach derived of a course of study agroekoteknologi the faculty agricultural
udayana university .Training followed followed by 69 participants. The trainers explained the material by the
use of a aids of power point and use specimens in the form of symptoms pest attacks .And continued with the
practice of the ground for 60 minutes .Each participant was given the task of search for plants citrus infested
by fruit flies and the cause. In the implementation of the training, farmers are very enthusiastic to follow

${ }^{1}$ Afiliansi dan e-mail penulis (italic, 9pt).

${ }^{2}$ Staf Pengajar Jurusan Teknik Elektro Fakultas Teknik Universitas Udayana, pengajar@ee.unud.ac.id 


\section{N. Wijaya dan W. Adiartayasa}

counseling. It is proven from many the questions asked.To know the success of this activity, so carried out evaluation with charging quisioner before and after training.

Keywords: training, fruit flies, citrus, their control

\section{PENDAHULUAN}

Pengabdian kepada masyarakat ini dilakukan di Kelompok Subak Abian Kerta Winangun Desa Katung, Kecamatan Kintamani, Kabupaten Bangli. Kelompok subak abian tersebut beranggotakan 97 petani jeruk. Desa Katung merupakan daerah sentra jeruk yang sangat produktif. Mata pencaharian penduduk Desa Katung sebagian besar sebagai petani terutama jeruk yang mencapai 90 $\%$ dari seluruh penduduk. Pertanaman jeruk di daerah ini sangat berhasil, sehingga pendapatannya meningkat. Namun belakangan, petani resah karena tanaman jeruknya terserang hama lalat buah.

Lalat buah Bactrocera spp. merupakan salah satu hama yang paling merugikan dalam budidaya tanaman buah-buahan maupun sayuran. Hama ini merugikan karena menyerang langsung produk pertanian yaitu buah. Serangan pada buah muda menyebabkan bentuk buah menjadi tidak normal, buah berkalus dan gugur. Serangan pada buah tua menyebabkan buah menjadi busuk basah karena bekas lubang larva umumnya terinfeksi bakteri dan jamur. Hasil penelitian kami (Wijaya dan Adiartayasa, 2016), menemukan empat spesies lalat buah dipertanaman jeruk di Desa Katung yaitu Bactrocera papayae, Bactrocera carambolae, Bactrocera umbrosus Fabricius, dan Bactrocera calumniata.

Sampai saat ini petani di Desa Katung belum memahami cara pengendalian hama lalat buah. Pengendalian yang sering dilakukan hanya menggunakan insektisida. Petani belum mengetahui penggunaan insektisida secara terus menerus akan menimbulkan pengaruh samping yang tidak diinginkan seperti resistensi hama, resurjensi, munculnya hama sekunder dan pencemaran lingkungan. Oleh karena itu perlu diadakan penyuluhan dan pelatihan tentang pengelolaan hama lalat buah pada tanaman jeruk.

\section{METODE PELAKSANAAN}

Penyuluhan dan pelatihan dilakukan dengan mengumpulkan Kelompok Subak Abian Kerta Winangun di Balai Desa Katung Kecamatan Kintamani, Kabupaten Bangli.. Peserta penyuluhan diberikan materi berupa makalah " Hama Lalat Buah dan Pengendaliannya pada Tanaman Jeruk ". Penceramah memaparkan materinya dengan menggunakan alat peraga berupa power point dan menggunakan spesimen berupa gejala serangan. Disamping itu penceramah memperlihatkan spesimen serangga lalat buah yang menyerang tanaman jeruk yang sudah diawetkan. Setelah 30 menit penyampaian materi, peserta diberikan waktu untuk berdiskusi. Kemudian penceramah melanjutkan dengan memperagakan gejala serangan pada buah jeruk yang terserang serta musuh alami yang berperan menekan perkembangannya. Selanjutnya peserta diberikan waktu untuk berdiskusi kembali. Agar tidak membosankan penceramah juga menyelipkan bahan lawakan agar peserta tidak mengantuk. Peserta diberikan waktu istirahat 30 menit sambil menikmati kudapan. Kemudian dilanjutkan dengan praktek lapangan selama 60 menit. Masing-masing peserta diberi tugas untuk mencari buah yang terserang lalat buah. Peserta yang masih salah disuruh mencari sampai benar.

Untuk mengetahui keberhasilan kegiatan ini, maka dilaksanakan evaluasi dengan yaitu : apakah petani jeruk di Desa Katung menambah pengetahuannya yaitu dengan melakukan pretest (pengetahuan sebelum dilakukan demplot) dan post test (pengetahuan setelah dilaksanakan denplot). Apabila terjadi peningkatan pengetahuan petani berarti pelatihan ini berhasil atau sebaliknya. 


\section{HASIL DAN PEMBAHASAN}

Kegiatan penyuluhan dan pelatihan serangan lalat buah pada tanaman jeruk serta pengendaliannya dilaksanakan tanggal 12 Agustus 2017 mulai pukul 10.00 samapai dengan 14.00 WITA, bertempat di Balai Banjar Katung, Kecamatan Kintamani, Kabupaten Bangli. Pelatihan ini dipandu oleh 4 (empat) orang pelatih (Gambar 1) yang berasal dari Program Studi Agroekoteknologi Fakultas Pertanian Universitas Udayana yaitu : 1). Prof.Dr.Ir. I Nyoman Wijaya, MS. bidang keahlian Ilmu Hama Tumbuhan. 2). Prof.Dr.Dra. Made Sritamin, MS. bidang keahlian Ilmu Hama Tumbuhan. 3). Prof.Dr.Ir. I Gde Putu Wirawan, M.Sc. bidang keahlian Ilmu Penyakit Tumbuhan. 4). Ir. Wayan Adiartayasa, M.Si. bidang keahlian Ilmu Penyakit Tumbuhan.

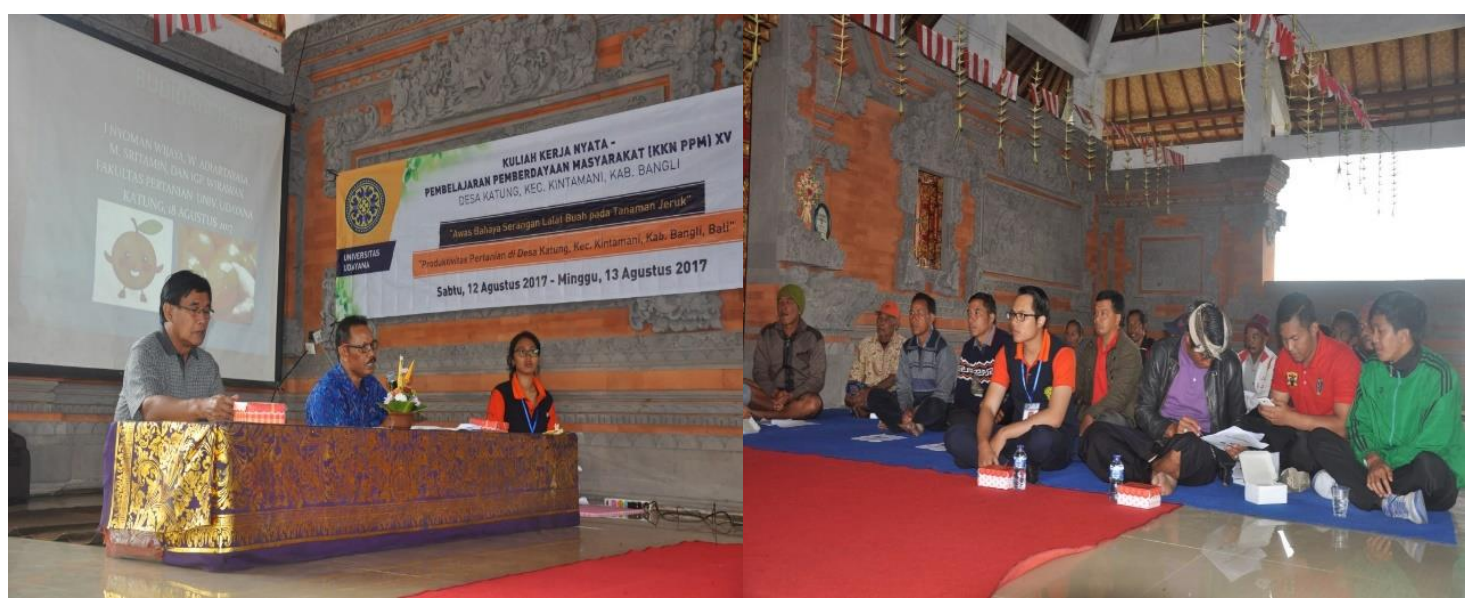

Gambar 1. Pelatih I Nyoman Wijaya dan Wayan Adiartayasa sedang menyampaikan materinya
Gambar 2. Peserta menyimak penjelasan dari pelatih dengan serius

Pelatihan diikuti diikuti oleh 69 orang peserta (Gambar 2). Pengelolaan hama dan penyakit jeruk sangat penting untuk diperhatikan dalam praktek budidaya, karena berpengaruh pada tingkat produksi dan produktivitas yang didapatkan. Produksi jeruk akan menurun dan bahkan gagal panen jika hama dan penyakit jeruk tidak dikelola dengan baik. Dalam pelaksanaan pelatihan tersebut, petani sangat antusias untuk mengikuti penyuluhan. Hal ini terbukti dari banyaknya pertanyaanpertanyaan yang diajukan. Dengan pelatihan ini petani banyak mendapat tambahan pengetahuan, sebaliknya pelatih juga mendapat pengalaman yang disampaikan petani. Setelah penyuluhan, petani diajak ke kebun jeruk milik petani. Ternyata buah jeruk banyak diserang oleh lalat buah. Pelatih menjelaskan gejala serangannya dan cara pengendaliannya.

\subsection{Gejala Serangan Lalat Buah}

Lalat buah betina menyerang buah dengan memasukkan telur melalui ovipositornya ke dalam buah. Pemasukan ovipositor ke dalam buah menyebabkan adanya gejala tusukan pada buah jeruk terlihat spot berwarna gelap cokelat kehitaman. Telur kemudian menetas menjadi larva yang hidup, makan dan berkembang di dalam buah sehingga buah menjadi busuk berisi larva atau dikenal dengan belatung (Gambar 3). Sesudah telur menetas, larva membuat lubang di dalam buah sehingga mempermudah masuknya bakteri dan cendawan (Siwi et al., 2006). Lalat buah hidup secara simbiosis mutualisme dengan bakteri, sehingga ketika lalat buah meletakkan telur pada buah, bakteri akan terbawa dengan diikuti cendawan yang akhirnya menyebabkan busuk. Sesudah telur menetas, larva mengorek daging buah sambil mengeluarkan enzim perusak atau pencerna yang berfungsi melunakkan daging buah sehingga mudah diisap dan dicerna. Enzim tersebut diketahui yang 
mempercepat pembusukan, selain bakteri pembusuk yang mempercepat aktivitas pembusukan buah. Buah yang terserang lalat buah dan busuk, akhirnya jatuh ke tanah Gambar 4.
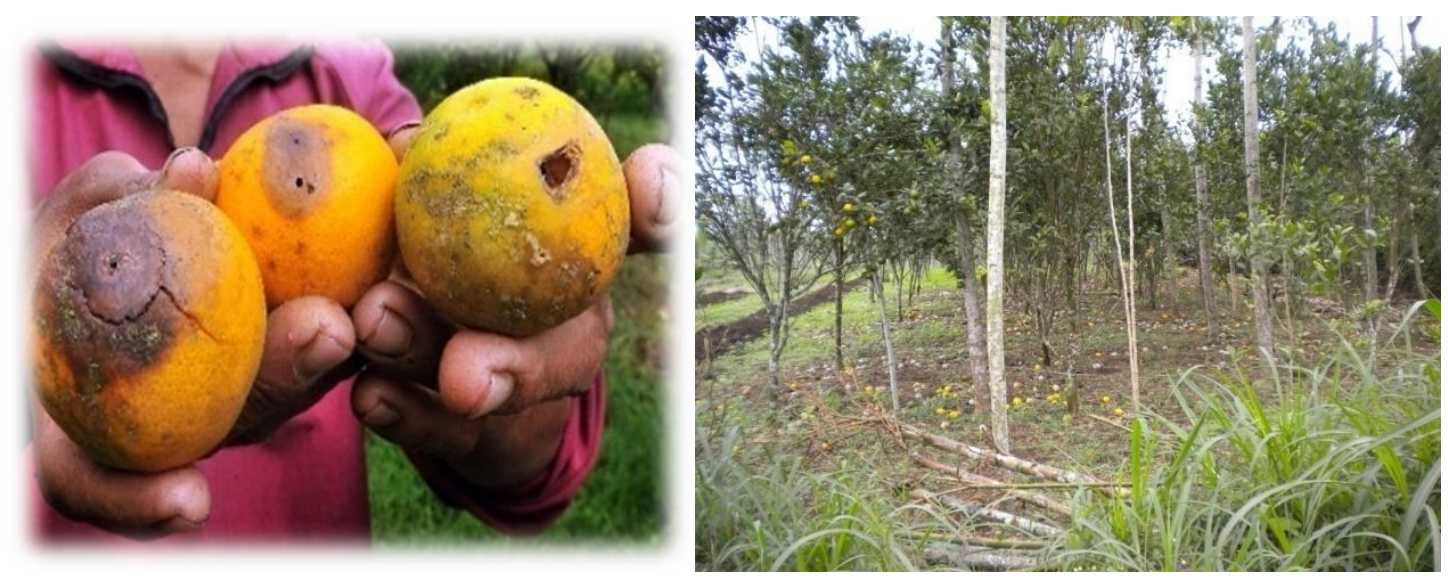

Gambar 3. Buah Jeruk Terserang Lalat Buah Gambar 4. Buah Jeruk Berjatuhan Karena Lalat Buah

Hasil penelitian kami (Wijaya dan Adiartayasa) tahun 2017, kerugian yang diakibatkan lalat buah sebesar Rp.29.468.750 per hektar. Lalat buah dapat dikendalikan dengan berbagai cara mulai dari mekanis, kultur teknis, biologi dan kimia. Di alam lalat buah mempunyai musuh alami berupa parasitoid dari genus Biosteres dan Opius dan beberapa predator seperti semut, sayap jala (Chrysopidae va. (ordo Neuroptera)), kepik Pentatomide (ordo Hemiptera) dan beberapa kumbang tanah (ordo Coleoptera). Pengendalian secara kultur teknis dapat dilakukan dengan pengolahan tanah (membalik tanah) di bawah pohon/tajuk tanaman dengan tujuan agar pupa terangkat ke permukaan tanah sehingga terkena sinar matahari dan akhirnya mati. Pengendalian dengan cara kimia dilakukan dengan menggunakan senyawa perangkap/atraktan yang dikombinasikan dengan insektisida. Senyawa yang umum digunakan adalah Methyl eugenol. Caranya dengan meneteskan pada segumpal kapas sampai basah namun tidak menetes, ditambah dengan insektisida dan dipasang pada perangkap yang sederhana. Alat perangkap terbuat dari dari botol bekas air minum mineral yang lehernya berbentuk kerucut atau toples plastik. Perangkap dipasang dekat pertanaman atau pada cabang atau ranting tanaman jeruk. Pemasangan dilakukan sejak buah pentil (umur 1,5 bulan) sampai panen. Pemberian cairan atraktan diulang setiap 2 minggu sampai 1 bulan. Setiap satu hektar dapat dipasang 15-25 perangkap.

Pada akhir kegiatan, diadakan uji untuk mengetahui seberapa jauh peningkatan pengetahuan dan keterampilan petani setelah dilakukan pelatihan.

\section{KESIMPULAN DAN SARAN}

Pengetahuan dan keterampilan petani mengalami peningkatan setelah diadakan pelatihan. Petani sudah bisa mengetahui gejala serangan hama dan penyakit pada tanaman jeruk serta cara penanggulangannya. Secara umum para peserta pelatihan menunjukkan respon yang positif terhadap kegiatan ini. Hal ini terlihat dari kesungguhan dan ketekunan peserta dalam mengikuti pelatihan. Pada saat penutupan pelatihan, Kepala Desa Katung meminta agar pelatihan seperti ini perlu dilanjutkan.

Mengingat hama lalat buah merupakan faktor penting dalam penurunan produksi jeruk, maka pelatihan tentang faktor-faktor yang mempengaruhi perkembangannya dan cara pengendaliannya perlu dilanjutkan sehingga penanganannya dapat dilakukan secara dini. 


\section{UCAPAN TERIMAKASIH}

Ucapan terimakasih disampaikan kepada Kepala Desa Katung yang telah memberi ijin untuk melaksanakan pengabdian dan petani jeruk Kelompok Subak Abian Kerta Winangun Desa Katung, atas waktunya mengikuti kegiatan pengabdian ini. Tidak lupa penulis juga mengucapkan terimakasih kepada LPPM atas dukungan berupa pendanaan sebesar 10 Juta rupiah pada skim Udayana Mengabdi tahun 2017.

\section{DAFTAR PUSTAKA}

Siwi, S.S. 2006. Taksonomi dan Bioekologi Lalat Buah Penting di Indonesia. Balai Besar Penelitian dan Pengembangan Bioteknologi dan Sumberdaya Genetik Pertanian. Bogor.

Wijaya, N. dan W. Adiartayasa. 2016. Komposisi dan Dinamika Populasi lalat Buah (Dipttera : Tephritidae) Pada Tanaman Jeruk. Laporan Penelitian. LPPM Unud.

Wijaya, N. dan W. Adiartayasa. 2017. Serangan dan Kerugian Lalat Buah, Bactrocera dorsalis Complex (Diptera : Tephritidae) pada Tanaman Jeruk. Laporan Penelitian. LPPM Unud. 